\title{
APLIKASI PERPUSTAKAAN DIGITAL PADA FAKULTAS TEKNOLOGI INDUSTRI UPN "VETERAN" YOGYAKARTA
}

\author{
Wisnu Tri Nugroho ${ }^{(1)}$, Nur Heri Cahyana ${ }^{(2)}$, Hidayatulah Himawan ${ }^{(3)}$ \\ ${ }_{(1,2,3)}$ Teknik Informatika \\ Universitas Pembangunan Nasional "Veteran" Yogyakarta \\ Tambakbayan 2 Babarsari, Yogyakarta \\ Email : if.iwan@gmail.com
}

\begin{abstract}
UPN Veteran Yogyakarta central library is already implementing information systems in libraries or short bias CYPRUS. However, the library information system only to simplify the process of borrowing and book search and have not been able to display books directly. Under the system, students or faculty who want to read the book should make the process of borrowing books or come directly to the library, so in terms of the efficiency of the service time of course it is less effective. In order for the service to library users more effective, it is necessary to Digital Library system that can accommodate the user needs to access a collection of books online. Construction of the Digital Library created first in small scale is devoted to the Faculty of Industrial Technology UPN Veteran Yogyakarta. Digital library is built using web-based programming with PHP + AJAX programming language and MySQL database. As for the appearance of the book pieces will be displayed in the form of animated Flash Slideshow. System analysis method of making this application is the Data Flow Diagram (DFD) to describe the flow of data and Entity Relationship Diagram (ERD) as a depiction of the relationships between the entities table.
\end{abstract}

\section{Keyword : Digital Library, PHP, Ajax, MySQL Database, Flash Slideshow}

Perpustakan pusat UPN Veteran Yogyakarta sebenarnya sudah menerapkan sistem informasi perpustakaan atau bias di singkat dengan SIPRUS. Namun, sistem informasi perpustakaan tersebut hanya untuk mempermudah proses peminjaman dan pencarian buku dan belum bisa untuk menampilkan buku secara langsung. Berdasarkan sistem tersebut, mahasiswa atau dosen yang ingin membaca buku harus melakukan proses meminjam buku atau datang secara langsung ke perpustakaan, sehingga dari segi efisiensi waktu pelayanan tentunya hal tersebut masih kurang efektif. Agar pelayanan kepada pengguna perpustakaan lebih efektif, maka diperlukan sistem Digital Library yang bisa mengakomodir keperluan pengguna untuk mengakses koleksi buku secara online. Pembangunan Digital Library ini dibuat terlebih dahulu dalam sekala kecil yang dikhususkan pada Fakultas Teknologi Industri UPN Veteran Yogyakarta. Digital library ini dibangun menggunakan pemrograman berbasis web dengan bahasa pemrograman PHP + AJAX dan database MySQL. Sedangkan untuk penampilan lembar buku akan ditampilkan dalam bentuk animasi Flash Slideshow. Metode analisa sistem dari pembuatan aplikasi ini adalah Data Flow Diagram (DFD) untuk menggambarkan aliran data dan Entity Relationship Diagram (ERD) sebagai penggambaran dari relasi antar entitas table.

Kata kunci : Perpustakaan Digital, PHP, Ajax, Database MySQL, Flash Slideshow

\section{PENDAHULUAN}

Perpustakaan Universitas Pembangunan Nasional "Veteran" Yogyakarta merupakan sarana pendukung dalam kegiatan belajar-mengajar. Secara umum fungsi dari perpustakaan Universitas Pembangunan Nasional "Veteran" Yogyakarta adalah institusi unit kerja yang menyimpan koleksi bahan pustaka secara sistematis dan mengelolanya secara khusus sebagai sumber informasi yang dapat digunakan oleh pemakainya. Universitas Pembangunan Nasional "Veteran" Yogyakarta memiliki dua buah perpustakaan yaitu perpustakaan ditingkat universitas dan perpustakaan ditingkat fakultas. Salah satunya adalah Perpustakaan Fakultas Teknologi 
Industri, yang menyediakan buku dan referensi sesuai dengan bidang ilmu masing-masing jurusan yang ada di fakultas tersebut.

Seiring berjalannya waktu, perpustakaan Fakultas Teknologi Industri UPN "Veteran" Yogyakarta terus mengalami perkembangan. Pertambahan koleksi yang ada akan menghambat civitas akademika dalam melakukan penelusuran referensi yang dibutuhkan terutama dari segi waktu. Masalah yang lain adalah koleksi dalam bentuk hardcopy memiliki keterbatasan akses serta pernyebarluasan. Ada kalanya saat membutuhkan satu referensi baik itu buku atau yang lain, tidak bisa ditemukan karena sedang dipinjam semua.

Diiringi dengan teknologi informasi yang kini hampir menjadi kebutuhan dan kecenderungan menggunakan teks secara elektronik terus meningkat dari hari ke hari, dari sinilah timbul sebuah ide untuk memanfaatkan teknologi informasi guna menyelesaikan persoalan di atas, dalam bentuk sebuah digital library atau perpustakaan digital.

\section{Perumusan Masalah}

Berdasarkan dari latar belakang di atas maka permasalahan yang dirumuskan adalah bagaimana membangun Perpustakaan Digital (Digital library) Fakultas Teknologi Industri UPN "Veteran" Yogyakarta?

Tujuan

Penelitian ini bertujuan untuk menghasilkan Aplikasi Perpustakaan Digital Berbasis Web sebagai sarana alternatif bagi mahasiswa atau pengguna dapat dengan mudah mengakses koleksi perpustakaan.

\section{TINJAUAN PUSTAKA}

\section{Aplikasi Web}

Aplikasi berbasis web merupakan sebuah aplikasi yang dapat diakses melalui internet atau intranet dan merupakan suatu aplikasi perangkat lunak komputer yang dikodekan dalam bahasa yang didukung penjelajah web (seperti HTML, JavasScript, Ajax, Java, dan lain lain) dan bergantung pada penjelajah tersebut untuk menampilkan aplikasi (_ _ http://id.wikipedia.org/wiki/Aplikasi_web. 2013).

Aplikasi web memberikan kelebihan untuk pengguna agar dapat lebih menghemat biaya daripada membeli aplikasi perkantoran dan menginstall perangkat lunak pada klien, untuk secara rutin upgrade software pada klien, dan untuk mempertahankan sistem operasi klien. Sebuah aplikasi web dapat berjalan pada Mac atau PC, pada Internet Explorer atau Firefox, sehingga mengurangi biaya untuk mendukung sebuah organisasi atau perusahaan. Beberapa kemudahan dan keuntungann lain dalam penggunaan aplikasi berbasis web antara lain:

1. Dapat diakses darimana dan kapan saja dengan menggunakan jaringan internet.

2. Bersifat Multi platform, yang dalam hal ini berartidapat digunakan pada sistem operasi apa pun, hal tersebut dikarenakan aplikasi berbasis Intranet/Internet dan diakses melalui browser, maka kita bisa mengakses aplikasi tersebut dengan sistem operasi apa pun, seperti system operasi Linux, Windows atau Mac OS

3. Program yang kita perlukan hanyalah browser (Mozilla Firefox, Internet Explorer maupun browser lainnya), jadi tidak perlu menginstall program lain. Hal ini memudahkan kita karena tidak perlu lagi menginstall untuk menggunakan suatu aplikasi.

4. Dapat diakses lewat banyak media seperti : komputer atau handphone yang sudah sesuai dengan standar WAP

5. Tidak perlu spesifikasi komputer yang tinggi untuk menggunakan aplikasi berbasis web.

6. Terkait dengan isu lisensi (hak cipta), kita tidak memerlukan lisensi ketika menggunakan web-based application, sebab lisensi itu telah menjadi tanggung jawab dari web penyedia aplikasi (seperti misalnya saat menggunakan MS-Office versi Google).

7. Selalu mendapatkan versi terbaru dari aplikasi. Karena aplikasi tersebut terpasang di server Intranet/Internet, perusahaan pembuat aplikasi bisa memperbarui aplikasinya terus-menerus. Begitu kita mengakses aplikasi itu, yang kita dapatkan pasti adalah versi terbaru.

Melihat kenyataan yang terjadi pada saat ini, dalam jangka waktu yang relatif singkat, Internet dan World Wide Web (biasa disebut dengan Web) telah berkembang dengan sangat pesat sehingga dapat melampaui kecepatan perkembangan teknologi lainnya di dunia. 
Internet dan Web juga berkembang pesat dalam hal jangkauan dan luas bidang kegunaan yang secara nyata mempengaruhi beberapa aspek kehidupan. Segala bidang kehidupan turut merasakan dampak dari perkembangan yang terjadi. Bidang Industri, Biro perjalanan, Rumah sakit, Perbankan, Pendidikan dan Pemerintahan menggunakan Web untuk meningkatkan efisiensi operasional dalam menjalankan fungsinya

(_ _, http://iocvo.wordpress.com, 2012).

\section{Basis Data}

Sistem basis data merupakan sekelompok komponen-komponen yang saling berinteraksi dan bekerja sama dalam mengelola sekumpulan data yang terdapat dalam suatu media penyimpanan serta menyediakan keluaran berupa informasi yang diolah dari data-data yang telah tersimpan. Penyusunan suatu basis data digunakan untuk mengatasi masalahmasalah yang timbul pada penyusunan data (Waljiyanto, 2003).

Struktur basis data meliputi tipe data, relationship (hubungan) dan constrain yang harus dipenuhi basis data. Basis data dapat diasumsikan sebagai lemari arsip yang memiliki kerja dan tujuan yang sama. Tujuan utama dari penggunaan basis data adalah kemudahan, kecepatan, efisiensi ruang penyimpanan, keakuratan, ketersediaan, kelengkapan, keamanan dan kebersamaan pemakai dalam pengambilan data atau arsip.

Sistem basis data merupakan sistem yang terdiri dari komponen file (tabel) yang saling berhubungan dan sekumpulan program data base management system (DBMS) yang memungkinkan beberapa pemakai data atau program lain untuk mengakses dan memanipulasi file-file (tabel-tabel) tersebut (Fathansyah, 1999).

Operasi-operasi dasar untuk manajemen data yang dapat dilakukan dengan database meliputi create database (pembuatan basis data baru), drop database (penghapusan basis data), create table (pembuatan file atau tabel baru), drop table (penghapusan file atau tabel), insert (penambahan atau pengisian data baru pada file), retrieve atau search (pengambilan data dari sebuah file), update (pengubahan data dari sebuah file), dan delete (penghapusan data dari sebuah file).

\section{Perpustakaan Digital}

Perpustakaan adalah infrastruktur yang sangat penting bagi suatu institusi,terlebih lagi pada suatu perguruan tinggi dimana pengembangan pendidikan menjadi focus utama. Perpustakaan memiliki beberapa definisi, salah satunya adalah bisa diartikan sebuah ruangan atau gedung yang digunakan untuk menyimpan buku dan terbitan lainnya yang biasanya disimpan menurut tata susunan tertentu yang di gunakan pembaca bukan untuk dijual (Sulistyo, 1991 ).

Aktifitas utama perpustakaan adalah menghimpun informasi dalam berbagai bentuk atau format untuk pelestarian bahan pustaka, sumber informasi dan sumber ilmu pengetahuan lainnya. Dengan seiring waktu perpustakaan pun berkembang menjadi beberapa jenis yang dibedakan menurut penyelenggaraan dan tujuannya, salah satunya adalah perpustakaan digital atau digital library.

Banyak definisi tentang perpustakaan digital yang dikemukakan oleh para ahli. The digital library initiatives menggambarkan perpustakaan digital sebagai lingkungan yang bersama-sama memberi koleksi, pelayanan dan manusia untuk menunjang kreasi, diseminasi, penggunaan dan pelestarian data, informasi dan pengetahuan. Sebagai perpustakaan yang berbeda dari sistem penelusuran informasi karena memiliki lebih banyak jenis media, menyediakan pelayanan dan fungsi tambahan, termasuk tahap lain dalam siklus informasi, dari pembuatan hingga penggunaan. Perpustakaan digital bisa dianggap sebagai institusi informasi dalam bentuk baru atau sebagai perluasan dari pelayanan perpustakaan yang sudah ada. Namun demikian perpustakaan digital sebagai koleksi informasi yang dikelola, yang memiliki pelayanan terkait, informasinya disimpan dalam format digital dan dapat diakses melalui jaringan. Sedangkan James Billington, pustakawan Library of Congress melukiskan perpustakaan digital sebagai sebuah koalisi dari institusi -institusi yang mengumpulkan koleksi koleksinya yang khas secara elektronik. (Purtini, 2005)

Pada tahun terakhir ini telah terjadi peledakan pertumbuhan ketertarikan dalam perkembangan dan pemakaian perp ustakaan digital. Beberapa faktor penunjangnya adalah:

1. Telah tersedianya teknologi komputasi dan komunikasi yang memungkinkan dilakukannya penciptaan, pengumpulan dan manipulasi informasi. 
2. Infrastruktur jaringan internasional untuk mendukung sambungan dan kemampuan pengopersian bagi pengguna.

3. Informasi online mulai berkembang.

4. Kerangka akses internet umum telah muncul.

Lebih jauh dikemukannya, perpustakan digital adalah koleksi data multimedia dalam skala besar yang terorganisasi dengan perangkat manajemen informasi dan metode yang mampu menampilkan data sebagai informasi dan pengetahuan yang berguna bagi masyarakat dalam berbagai konteks organsiasi dan sosial masyarakat. (Griffin, 1999).

\section{Masalah Perpustakaan Digital}

1. Digitalisasi Dokumen

Romi Satrio Wahono (2006) mengatakan bahwa pengelolaan dokumen elektronik memerlukan teknik khusus yang memiliki perbedaan dengan pengelolaan dokumen tercetak. Proses pengelolaan dokumen elektronik melewati beberapa tahapan, antara lain dalam proses digitalisasi,penyimpanan dan pengaksesan/ temu kembali dokumen. Pengelolaan dokumen elektronik yang baik dan terstruktur adalah bekal penting dalam pembangunan sistem perpustakaan digital.

Proses perubahan dari dokumen tercetak (printed documents) menjadi dokumen elektronik sering disebut dengan proses digitalisasi dokumen. Proses digitalisasi dokumen dimulai dengan dokumen mentah (jurnal, prosiding, buku, majalah, dan sebagainya) diproses dengan sebuah alat (scanner) untuk menghasilkan dokumen elektronik. Proses digitalisasi dokumen ini tentu tidak diperlukan lagi apabila dokumen elektronik sudah menjadi standar dalam proses dokumentasi sebuah organisasi.

\section{Hak Cipta}

Hak cipta pada dokumen yang didigitalkan yang berupa mengubah dokumen menjadi digital dokumen, memasukkan digital dokumen ke database, mengubah digital dokumen ke hypertext dokumen. Hak cipta dokumen di jaringan komunikasi. Solusi masalah hak cipta telah dikembangkan dalam ECSM (Electronic Copyright Management System) yaitu sistem monitoring penggunaan digital dokumen oleh pengguna secara otomatis (_ , http://id.wikipedia.org/wiki/Perpustakaan_digital, 2012).

\section{Penarikan Biaya}

Masalah yang terjadi pada perpustakaan digital swasta yang menarik biaya setiap mengakses dokumen. Solusi masalah ini akan dikembangkan pada system electronic money (_ _http://id.wikipedia.org/wiki/Perpustakaan_digital, 2012).

\section{Indonesia Digital Library Network (IndonesiaDLN)}

Perkembangan perpustakaan digital di indonesia cukup pesat terutama di lingkungan perpustakaan perguruan tinggi. Jaringan perpustakaan digital di Indonesia dikenal dengan Indonesia Digital Library Network (IndonesiaDLN). Perkembangan IndonesiaDLN cukup pesat diantaranya alam publikasi IDRC disebutkan bahwa pada tanggal 2 Februari 2002, International Development Research Centre (IDRC) yang berpusat di Kanada, pada tanggal 26-27 Desember 2001 telah mengadakan wawancara dengan Principal Investigator penelitian IndonesiaDLN dan Tim KMRG. Wawancara ini untuk mempublikasikan pengalaman project yang didanai oleh IDRC (dan YLTI) dalam membangun digital library dan mendorong pembentukan komunitas IndonesiaDLN, khususnya setelah mendapat penghargaan dari ASIST. Laporan wawancara yang dibuat oleh Mr. Chin Saik Yoon dari Southbond Penang ini diharapkan dapat meningkatkan reputasi IndonesiaDLN di tingkat Internasional serta meningkatkan semangat kita untuk terus maju dalam mengembangkan digital library di Indonesia.

Pertemuan tahunan ketiga IndonesiaDLN pada tanggal 1 Februari 2002, IndonesiaDLN mengadakan pertemuan tahunan ketiga. Tema pertemuan ini adalah "Establishing Collaboration for a Networked Information Society", atau Membangun Kerjasama untuk Sebuah Masyarakat Informasi Berbasis Jaringan. Pada pertemuan tersebut, para peserta saling bertukar gagasan, pengalaman, maupun keahlian untuk menggali potensi bangsa Indonesia dalam bentuk informasi dan ilmu pengetahuan. Bagaimana strategi dan praktek terbaik untuk mengumpulkannya dan bagaimana menyebarkannya bagi kemaslahatan hidup bangsa. Proposal pembentukan konsorsium IndonesiaDLN 1 Februari 2002. Setelah berjalan selama dua tahun lebih, IndonesiaDLN melangkah ke babak baru. Yaitu pembentukan sebuah 
konsorsium yang lebih dapat diharapkan untuk mendorong pengembangan digital library dan sharing pengetahuan di Indonesia.

\section{Geany}

Geany adalah sebuah IDE yang sangat kecil dan ringan, dan IDE yang tidak membutuhkan depedency yang banyak untuk mengistallnya. Syarat yang di perlukan untuk menginstall geany adalah runtime library GTK2. Geany adalah Software multi platform, yang artinya geany bisa running di Linux, FreeBSD, NetBSD, OpenBSD, MacOS X, AIX V5.3, Solaris Express dan Windows dan geany menggunakan GNU General Public License Sebagai lisensinya. ,http://theomaulida.wordpress.com, 2012).

\section{Studi Pustaka}

Penelitian sejenis pernah dilakukan oleh I Kadek Bayu Dwi Saputra dari Universitas Pembangunan Nasional "Veteran" Yogyakarta berjudul Sistem Informasi Perpustakaan Berbasis Web Fakultas Teknologi Industri UPN Veteran Yogyakarta pada tahun 2011. Pada penelitian tersebut yang dibuat adalah sistem informasi perpustakaan Fakultas Teknologi Industri UPN Veteran Yogyakarta berbasis web dan metode pengembangan software yang digunakan adalah metode Waterfall (Siklus Air Terjun). Pada penelitian tersebut yang dibuat adalah pelayanan perpustakaan seperti pendaftaran anggota, peminjaman buku, pengembalian buku, dan penyimpanan koleksi buku, yang bertujuan menunjang pelayanan peminjaman dan pengembalian. Layanan terekam dalam database untuk mempermudah pencarian.

Perbedaan penelitian ini dengan penelitian yang sudah ada adalah pelayanan perpustakaan dalam bentuk koleksi digital yang dapat diakses dari jarak jauh, dan dalam perpustakaan digital ini, koleksinya pun juga tidak lagi dalam bentuk tercetak. Hal ini dikarenakan adanya pendigitalan dokumen yang dapat ditampilkan dalam web sebagai alternatif pengganti perpustakaan secara fisik. koleksi digital dan perpustakaan tersebut dapat diakses selama 24 jam sehari dan 7 hari seminggu baik di dalam perpustakaan maupun jarak jauh tanpa harus datang ke perpustakaan secara fisik.

\section{METODE PENELITIAN}

Metodologi pengembangan sistem yang digunakan untuk membangun aplikasi ini adalah waterfall yang terdiri dari beberapa tahap yaitu :

1 Analisis dan Rekayasa Sistem

2 Perancangan (Design)

3 Penulisan Program (Coding)

4 Pengujian (Testing)

5 Pemeliharaan (Maintenance)

Dalam penelitian ini hanya di lakukan sampai tahapan Pengujian (Testing).

\section{HASIL DAN PEMBAHASAN}

\section{1. $\quad$ Perangkat Lunak yang Digunakan}

Untuk merancang aplikasi ini dibutuhkan beberapa perangkat lunak pendukung.

Adapun perangkat lunak yang digunakan untuk mengimplementasikan aplikasi ini adalah:

1. Sistem Operasi yang digunakan adalah Linux Ubuntu 12.04 Precise Pangolin.

2. Web Server menggunakan Apache 2.2.12.

3. Database server mengguakan MySQL versi 5.5.8.

4. Web Browser yang digunakan adalah Mozila Firefox.

5. Bahasa Pemograman yang digunakan adalah PHP (PHP Hypertext Processor).

6. Program pendukung yang digunakan untuk sistem ini adalah Sublime Text 2.

\subsection{Halaman Beranda (Homepage User)}

Halaman beranda merupakan halaman awal ketika user memasukkan alamat website untuk pertamakali. Tampilan halaman beranda dapat dilihat pada gambar 5.1. 


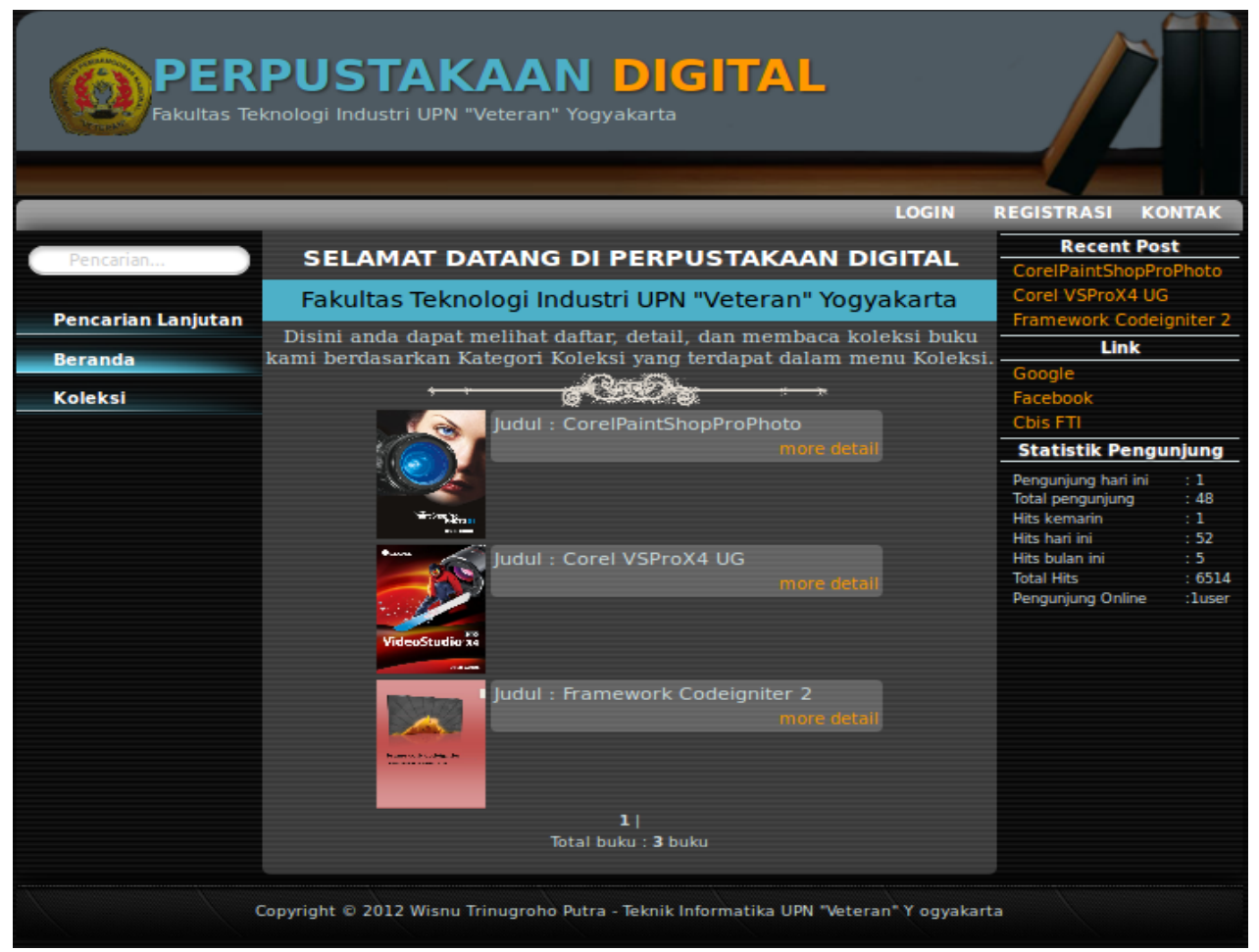

Gambar 4.1 Halaman Beranda

Listing program halaman beranda dapat dilihat pada modul di bawah ini :

$<$ body $>$

$<$ div class=header $>$

$<$ div id="site_title">

$<$ div id="logo" $><$ /div $>$

$<$ h1 >PERPUSTAKAAN $<$ span $>$ DIGITAL $<$ span $></$ h1 $>$

$<$ h2>Fakultas Teknologi Industri UPN "Veteran" Yogyakarta</h2>

$<$ div id="clear" $><$ div $>$

$<$ div $>$

$</$ div $>$

$<$ div class=menu $>$

$<$ div class $=$ menu $1>$

$<$ ul $>$

$<$ li $>$

$<$ a id="login" href="fti_digilib.php?mod=login" class="<?= (\$_GET['mod'] == 'login') ? 'current' : ";

?>">Login </a>

$</$ li $>$

$<$ li $>$

$<$ a id="registrasi" href="fti_digilib.php?mod=registrasi" class="<?= (\$_GET['mod'] == 'registrasi')

? 'current' : "; ?>">Registrasi</a>

$</$ li $>$

$<\mathrm{li}>$

$<$ id="Kontak" href="fti_digilib.php?mod=kontak" class="<?=(\$_GET['mod'] == 'contact') ?

'current' : "; ?>">Kontak</a> $</$ li $>$

$</$ ul $>$

$</$ div $>$

$</$ div $>$

$<$ div class=page $>$

$<$ div class $=$ sideleft $>$

$<$ ul>

<form class="quick_search"> 


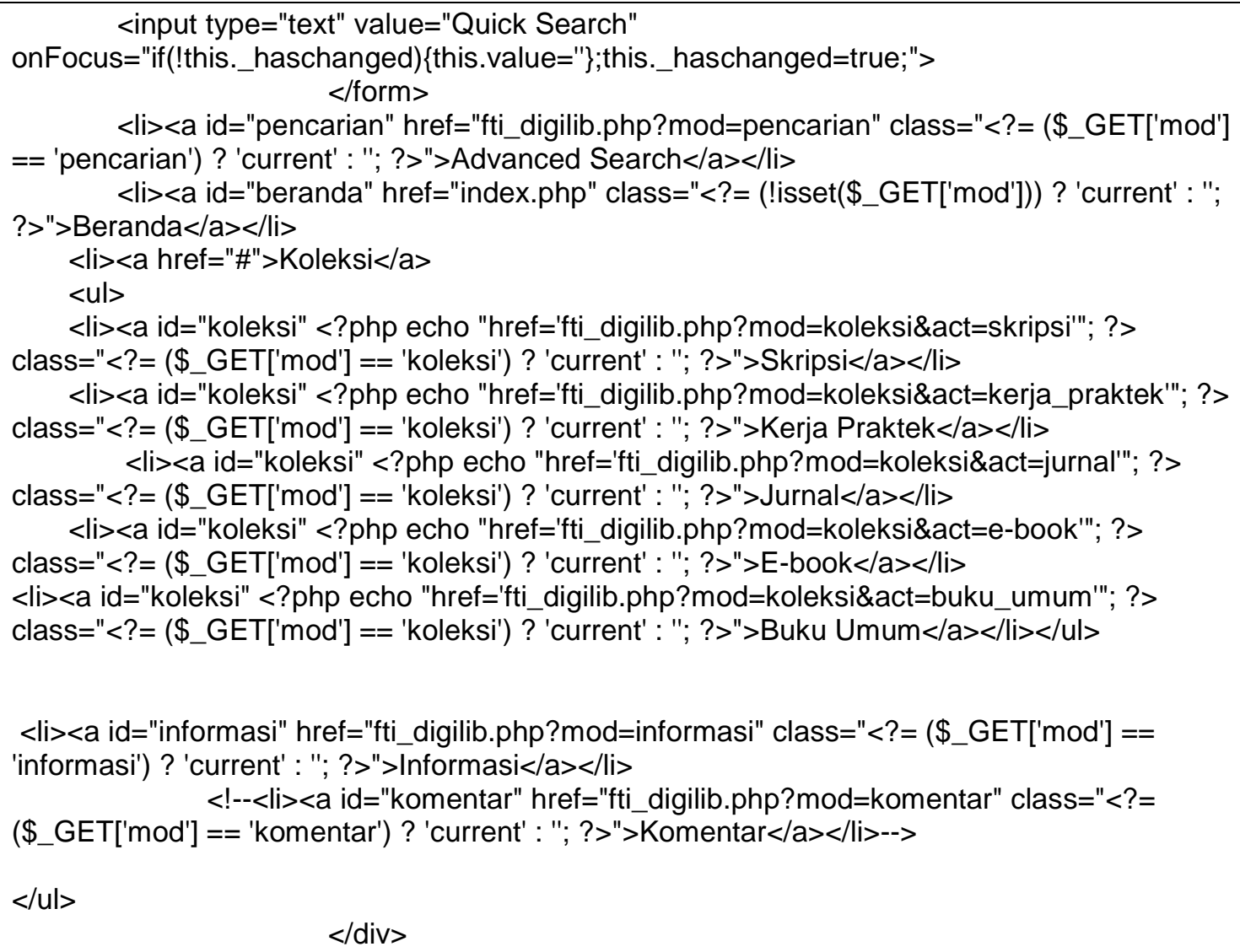

Modul Program 4.1 Source Code Halaman beranda

\subsection{Halaman Beranda Admin}

Halaman beranda admin adalah halaman yang akan tampil setelah admin melakukan login. Login admin di lakukan di dalam halaman login. Tampilan halaman beranda admin dapat dilihat pada gambar 4.2 .

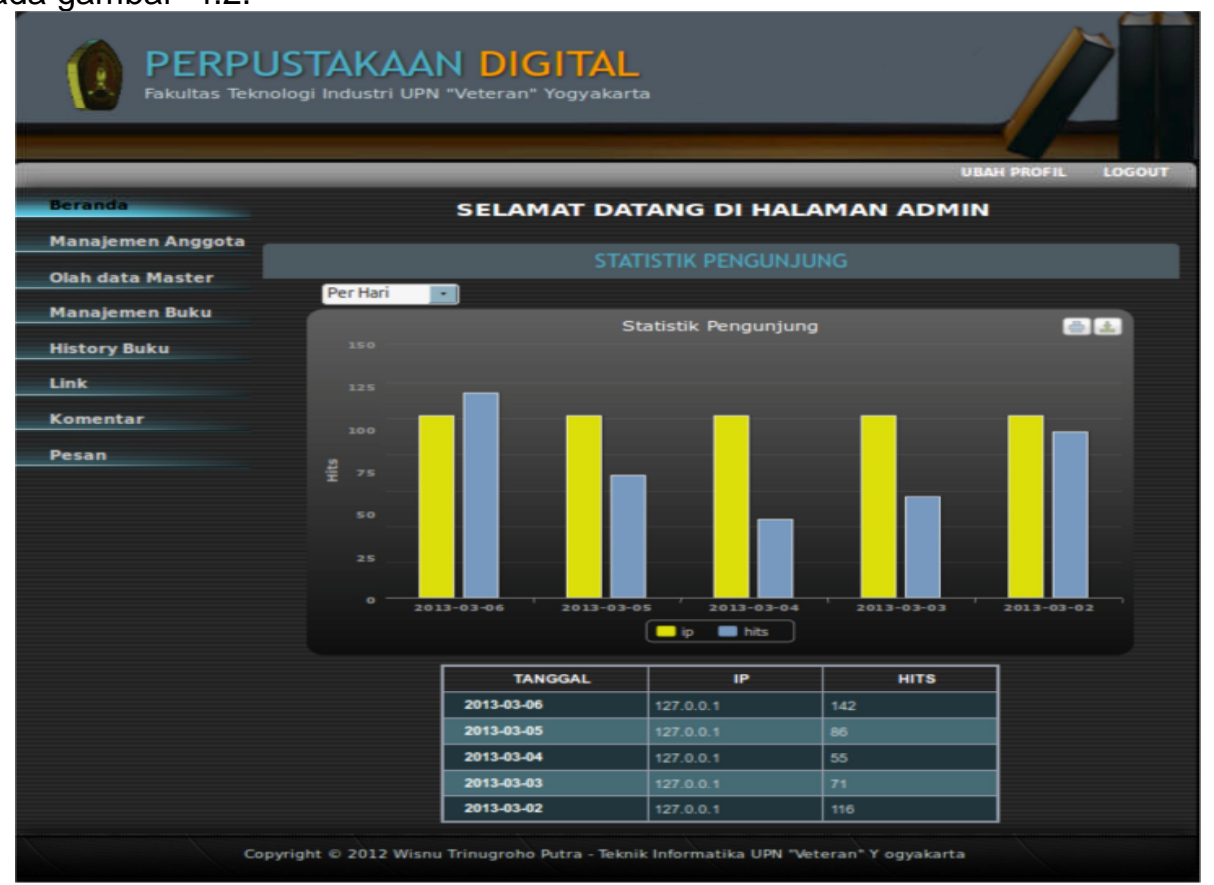

Gambar 4.2. Halaman Beranda Admin 


\section{KESIMPULAN}

Berdasarkan hasil penelitian yang telah dilakukan, maka dapat diambil kesimpulan bahwa telah dihasilkan suatu aplikasi perpustakaan digital Fakultas Teknologi Industri UPN "Veteran" Yogyakarta, yang berfungsi dari aplikasi ini adalah memberikan kemudahan dalam penelusuran referensi bagi mahasiswa, serta sebagai alternatif pengganti perpustakaan secara fisik.

\section{Saran}

Berdasarkan aplikasi yang telah dibangun, saran yang diajukan berkaitan dengan pengembangan penelitian selanjutnya yaitu penyempurnaan mesin pencarian agar lebih mudah di temukan, serta pemakaian metadata sesuai standart nasional.

\section{DAFTAR PUSTAKA}

Basuki, Sulistyo, 1991, Pengantar Ilmu Perpustakaan, Gramedia, Jakarta.

Fathansyah, 1999, Basis Data, Informatika, Bandung.

Griffin, An Architecture for Collaborative Math and Science Digital Libraries, MS thesis (Virginia

Tech Department of Computer Science, Blacksburg, VA, 1999).

Jogiyanto, HM, 2001, Analisis Perancangan Sistem Informasi, Andi Offset, Yogyakarta

Pressman, Roger S, 2002, Rekayasa Perangkat Lunak Pendekatan Praktisi, Buku Satu, Andi Offset, Yogyakarta.

Pressman, Roger S, 2010, Software Engineering - A Practitioner's Approach $7^{\text {th }}$ Edition, McGraw-Hill,New York.

Purbo, 2006, Buku Pegangan Internet Wireless dan Hotspot, Elek Media Komputindo, Jakarta.

Purwadi, Daniel H, 1997, Mengenal Internet Jaringan Informasi Dunia, Elex Media Computindo, Jakarta.

Purtini. Winy, Perpustakaan digital, http://www.indonesiadln.org/wiki/inde x.php/ Main Page

Saleh, Nurachman, Perpustakaan sebagai Jembatan Pengetahuan, dalam Seminar Nasional Jaringan Dokumentasi dan Informasi di Era Informasi/Masyarakat berpengetahuan 2004 (Surabaya: Perpustakaan Ubaya, 2004).

Sidik, Betha, 2011, JavaScript, Informatika, Bandung

Sutarman, 2003, Membangun Aplikasi Web dengan PHP dan MySql, Graha IImu, Yogyakarta

Waljiyanto, 2003, Sistem basis data: analisis dan pemodelan data, Graha IImu, Yogyakarta

Winarno E, Zaki A, 2011, Easy Web Programming with PHP plus HTML 5, Elex Media Komputindo

,http://ivan maurits.staff.gunadarma.ac.id, 2012/ 8 Nopember 2012

, http://iocvo.wordpress.com/2012/04/14/mengapa-aplikasi-berbasis-web/

8 Nopember 2012

,http://arist-pras.blogspot.com/2010/12/macam-macam-pemrograman-web.html/

8 Nopember 2012

,http:// theomaulida.wordpress.com/2012/04/20/introduce-geany/ 8 Nopember 2012.

, http://id.wikipedia.org/wiki/Perpustakaan_digital/ 8 Nopember 2012

, http://id.wikipedia.org/wiki/Aplikasi web/ 12 Januari 2013

,http://id.wikipedia.org/wiki/Cascading_Style_Sheets, 25 Desember 2012

,http://id.wikipedia.org/wiki/MySql, 25 Desember 2012 